\title{
Effect of intra-articular corticosteroid injections on primate cartilage
}

\author{
T. GIBSO N, H. C. BURRY, D. POSWILLO*, AND J. GLASS
}

From Guy's Arthritis Research Unit, Guy's Hospital Medical School, London, and the Royal College of Surgeons Research Establishment, Downe, Kent*

SUMMARY An attempt was made to ascertain whether intra-articular corticosteroids exert a harmf 药 effect on primate cartilage. The knee joints of 10 Macaca irus monkeys were subjected to either onej two, or six injections of $20 \mathrm{mg}$ methyl prednisolone or an equal number of control injections over a 12-week pericd. Minor degenerative changes of many femoral condyles were shown by India in staining and by a system of histochemical grading. Changes in the joints injected with corticosteroig were not significantly different from those seen in control joints. The findings were in striking contrast to the severe degeneration reported by others in rabbit joints injected with corticosteroid. The experiment did not support the contention that intra-articular corticosteroids invariably have deleterious effect on primate cartilage.

The use of intra-articular corticosteroid injections in the treatment of joint disorders remains controversial. Although widely used in the management of joint i nflammation, evidence that they may accelerate cartilage destruction in man (Chandler and Wright, 1958) and rabbits (Salter et al., 1967) has deterred universal acceptance.

Many reports describing harmful effects in man have been of isolated cases subjected to frequent injections (Chandler et al., 1959; Steinberg et al., 1962) and the induction of degenerative changes in rabbit joints is dependent on the frequency of injections (Salter et al., 1967). Furthermore, the response of different species to corticosteroids is varied (Rehder and Enquist, 1967), and to what extent the observed effect on rabbit articular cartilage can be applied to man is uncertain.

This study was designed to assess the effect of intra-articular methyl prednisolone on the articular cartilage of a primate model (Macaca irus monkey) in the expectation that the results would have more relevance to man than animal experiments hitherto.

\section{Method}

Ten mature monkeys (M. irus) of approximately equal age and size (mean weight $5.7 \mathrm{~kg}$ ) were selected

Accepted for publication May 2, 1976

Correspondence to Dr. T. Gibson, Guy's Arthritis Research Unit, Guy's Hospital Medical School, London Bridge, London SE1 9RT for the experiment. Throughout the study they were fed a pathogen-free balanced diet suitable fof humans. Using strict aseptic precautions and with the animals sedated with phencyclidine or ketaming hydrochloride, $0.5 \mathrm{ml}(20 \mathrm{mg})$ methyl prednisolon: was injected into one knee joint of each animal. A equivalent volume of vehicle used in the same commercial preparation of methyl prednisolone was injected into the opposite knee. The vehicle consisted of polyethylene glycol $29 \mathrm{mg}$, sodium chloride $8.7 \mathrm{mg}$ mynistylgamma picolinium chloride $0.19 \mathrm{mg}$, and water to $1 \mathrm{ml}$. The accurate placing of the injections was confirmed by adding $0.2 \mathrm{ml}$ of a radio-opaque dye (Conray) to the injection fluid and performin $x$-rays immediately after injection.

Tibial biopsies were obtained from both knees of 2 animals 4 weeks later and injections were repeated at the same time in the other 8 animalss 4 of these underwent a further series of four injec tions into each knee at 2-week intervals (total of injections). $X$-rays of the joints were taken immeder ately before the experiment and again 14 weeks late at which time all 10 animals were sacrificed.

The surfaces of the femoral condyles, menisci and tibiae were examined with the naked eye fas surface defects. The fresh femoral specimens were्p coated with India ink diluted with physiologicas saline, examined for evidence of fibrillation in the manner described by Bullough and Goodfellow (1968) and then photographed.

The biopsies and the whole joints were fixed if 
Table 1 Details of the histological-histochemical grading method used to establish a score for each joint

\begin{tabular}{llll}
\hline Score & Structure & Cells & Staining intensity (Alcian blue) \\
\hline 0 & Normal & Normal & Normal \\
1 & Surface irregularities & Diffuse increase & Slight decrease \\
2 & Clefts to midzone & Cloning & Moderate decrease \\
3 & Clefts to calcified zone & Hypocellularity & \\
4 & Complete disorganization & & \\
\hline
\end{tabular}

formalin and decalcified. With the guidance of earlier photographs, sections were cut through areas of macroscopical abnormality and adjacent areas on the femoral condyles. Where no naked eye abnormality was apparent, sections were obtained through similar anatomic sites on the medial condyles.

Thin sections were obtained after embedding in paraffin wax. These were stained with haematoxylin and eosin and with Alcian blue $0.1 \%$ in $0.05 \mathrm{~mol} / 1$ acetate buffer $\mathrm{pH} 5.8$, containing $\mathrm{MgCl}_{2}$ at concentrations ranging from $0.3 \mathrm{~mol} / \mathrm{l}$ to $0.9 \mathrm{~mol} / \mathrm{l}$. The latter critical electrolyte concentration technique stains both chondroitin sulphate and keratan

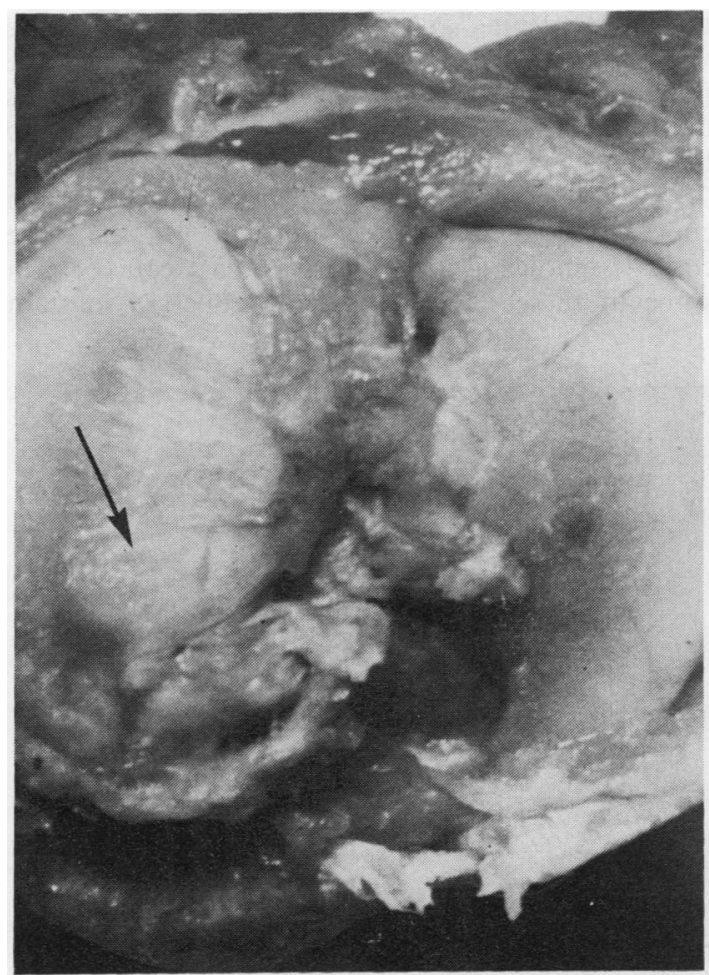

Fig. 1 Repair of tibial biopsy site by fibrocartilage (arrow) 10 weeks after biopsy. sulphate at low concentrations of magnesium chloride but a concentration of $0.9 \mathrm{~mol} / 1$ detects only keratan sulphate (Scott and Dorling, 1965).

A system of histochemical grading was modified from that of Mankin et al., (1971) (Table 1). The histological specimens were reviewed separately by two of us (T. G., H. B.) without knowledge of the source of the material.

\section{Results}

$X$-rays taken before and on completion of the study showed no radiological abnormality of any of the joints. Tibial biopsies obtained 4 weeks after the initial injections had a normal macroscopical appearance and sections stained with haematoxylin and eosin showed no abnormality of either the two

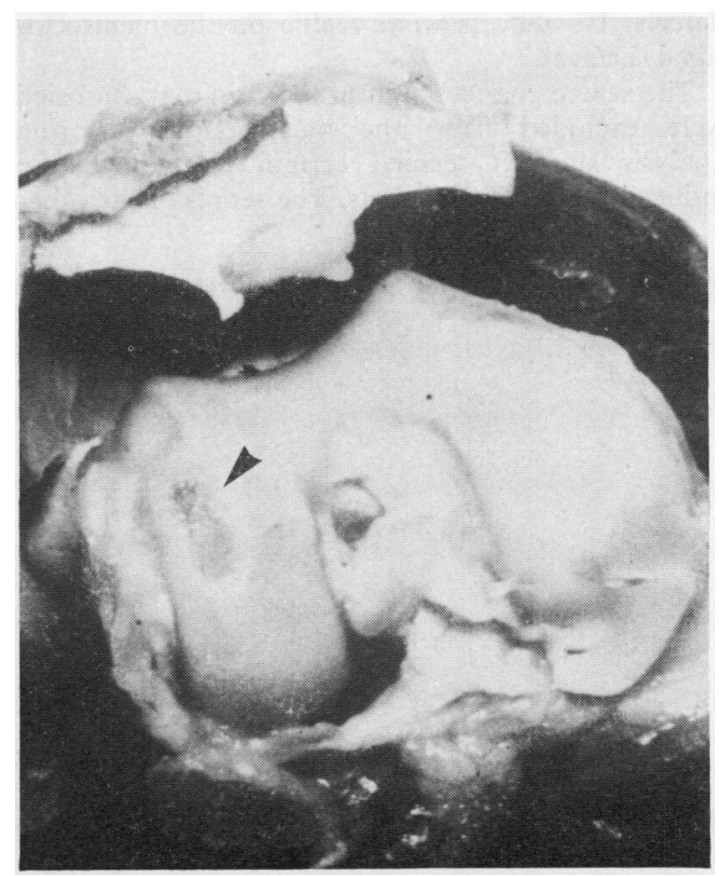

Fig. 2 Ulceration of femoral condyle (arrow) in monkey subjected to tibial biopsy 10 weeks previously. 
Table 2 Macroscopical scores in 8 animals receiving two or six injections

\begin{tabular}{lll}
\hline Monkey & \multicolumn{2}{l}{ Macroscopical score } \\
\cline { 2 - 3 } & Steroid & Control \\
\hline 2 injections & & \\
C & 0 & 1 \\
D & 1 & 1 \\
E & 1 & 3 \\
F & 0 & 1 \\
Total & 2 & 6 \\
6 injections & & \\
G & 1 & 6 \\
H & 2 & 0 \\
I & 2 & 4 \\
J & 5 & 0 \\
Total & 10 & 10 \\
\hline
\end{tabular}

joints receiving one injection of steroid or the two lcontrol joints. At 14 weeks the biopsy defects were a rgely repaired by fibrocartilage (Fig. 1). However, examination of the femoral condyles of these 2 animals showed marked surface irregularities with cartilage roughening and ulceration (Fig. 2). The extent of these changes was identical in all four joints.

Macroscopical changes of this severity were not seen on the femoral condyles of the remaining 8 animals. These were either absolutely smooth or showed small areas of slight roughening or linear defects. No defects were visible on the menisci or tibial surfaces.

The severe changes seen in the 2 animals biopsied were excluded from the macroscopical scoring analysis since it seemed certain that they were induced by the tibial defects. The scores of the other
8 animals are given in Table 2., A slightly higher total score of 16 was obtained in the control joints compared with 12 for the steroid injected joints. The average score of the joints receiving six injections? was the same in both steroid injected and contro? joints $(2 \cdot 5)$ but was higher than the average score of the joints receiving two injections $(1 \cdot 0)$.

A variety of histological changes was observed? ranging from a normal appearance to surfaces defects, cartilage clefts, cloning of chondrocytes $\overrightarrow{0}$ and hypocellularity. The joints subjected to biopsyshowed clefts in all four sections but the cellularw configuration and staining densities were similar tos those of several other animals and so their histo chemical grading was incorporated in the total scores

Cartilage clefts with and without cloning of chondrocytes were observed in five other joints. $-A$ Such changes were not predominant in either theo steroid injection or control joints. The knee joints of one animal not included in the experiment and which had received no injections showed clefts similar to those seen in the experimental animals (Fig. 3) when examined.

Alcian blue stain at $0.3 \mathrm{~mol} / 1$ concentration was considerably denser than at $0.9 \mathrm{~mol} / 1$, and in someinstances staining at the higher concentration was very faint. In general, differences between theo joints were subtle and grading of stain intensity was difficult. There was no consistent relationship between the density of staining at $0.3 \mathrm{~mol} / \mathrm{l}$ anco $0.9 \mathrm{~mol} / \mathrm{l}$. Decreased staining density at one or both concentrations was noted in eight of the nines condyles showing clefts and was least equivocal in some of these. However, some reduction in stain

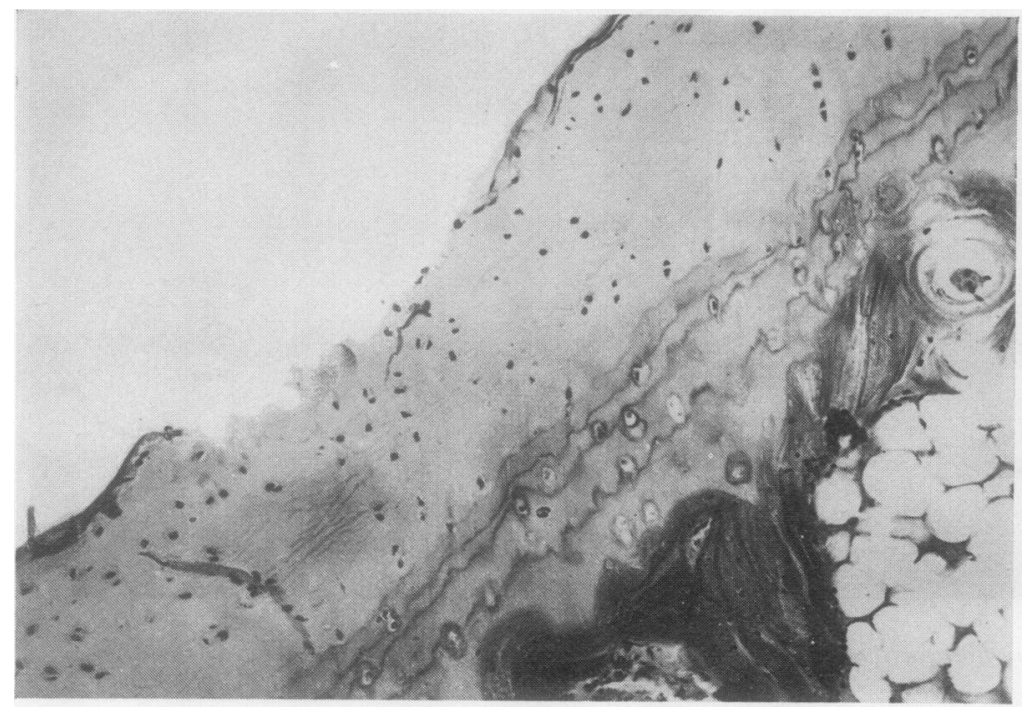

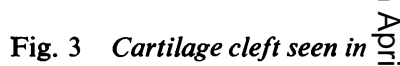
femoral condyle of monkey not included in the experiment $\mathrm{N}$ and identical to that observed $\mathrm{N}$ in some of the experimental animals. Haematoxylin and eosin $\times 76$. 
Table 3 Detailed results of the histological-histochemical grading of 20 knee joints injected with methyl prednisolone or vehicle

\begin{tabular}{|c|c|c|c|c|c|c|c|c|}
\hline \multirow[t]{3}{*}{ Monkey } & \multicolumn{2}{|c|}{ Structure } & \multicolumn{2}{|l|}{ Cells } & \multicolumn{4}{|c|}{ Staining intensity (Alcian blue) } \\
\hline & \multirow[t]{2}{*}{ Steroid } & \multirow[t]{2}{*}{ Control } & \multirow[t]{2}{*}{ Steroid } & \multirow[t]{2}{*}{ Control } & \multicolumn{2}{|c|}{$0.3 \mathrm{~mol} / \mathrm{l} \mathrm{MgCl}_{2}$} & \multicolumn{2}{|c|}{$0.9 \mathrm{~mol} / \mathrm{l} \mathrm{MgCl}_{2}$} \\
\hline & & & & & Steroid & Control & Steroid & Control \\
\hline \multicolumn{9}{|l|}{1 injection } \\
\hline A & 2 & 2 & 3 & 2 & 1 & 1 & 3 & 1 \\
\hline B & $\overline{2}$ & 2 & 2 & $\overline{1}$ & 3 & 3 & 2 & 1 \\
\hline \multicolumn{9}{|l|}{2 injections } \\
\hline C & 1 & 1 & 0 & 1 & 2 & 3 & 1 & 0 \\
\hline $\mathbf{D}$ & 0 & 0 & 2 & 0 & 1 & 0 & 0 & 1 \\
\hline $\mathbf{E}$ & 0 & 2 & 0 & 3 & 0 & 0 & 1 & 2 \\
\hline $\mathbf{F}$ & 2 & $\mathbf{0}$ & 2 & 2 & 2 & 2 & 2 & 3 \\
\hline Total & 3 & 3 & 4 & 6 & 5 & 5 & 4 & 6 \\
\hline \multicolumn{9}{|l|}{6 injections } \\
\hline $\mathbf{G}$ & 1 & 1 & 0 & 0 & 0 & 0 & 1 & 0 \\
\hline $\mathbf{J}$ & 2 & 0 & 2 & 1 & 2 & 2 & 2 & 1 \\
\hline Total & 5 & 3 & 5 & 1 & 4 & 4 & 8 & 6 \\
\hline
\end{tabular}

intensity was also seen in three joints with no or minimal structural changes.

The results of histochemical grading obtained by the two observers were in agreement and are summarized in Table 3. The average total score for all the histochemical parameters in the 2 animals injected once only was $\mathbf{9 . 0}$ for the steroid injected joints and 6.5 for the control joints. In the 4 animals injected twice the average total score was 4.0 for the steroid joints and 3.5 for the controls. Thus the highest average total scores were seen in the joints injected once and subjected to tibial biopsies. Differences between the steroid injected and control joints were small in each of these groups and the mean $( \pm S D)$ total scores for the 10 animals were $5.6 \pm 3.03$ for the joints injected with steroid and 4.7 \pm 2.36 for the control joints. The difference was not significant ( $P=0 \cdot 17$; binomial test).

\section{Discussion}

With few exceptions the weight of evidence incriminating intra-articular corticosteroids in the acceleration of joint destruction in man is based on anecdotal reports. Chandler et al., (1959) recorded a single case of accelerated osteoarthrosis in a hip injected repeatedly with hydrocortisone. A similar case was reported by Sweetnam et al., (1960) although only three injections were given in the latter case compared with 18 in the former. Zachariae (1965) also reported rapid deterioration in knees or hips of 4 patients receiving intra-articular injections with as many as 50 injections over one year in one case. A Charcot-like arthropathy was observed by Steinberg et al. (1962) in a rheumatoid knee injected with hydrocortisone on 22 occasions over a 2-year period and identical changes were reported in both knees of a patient who had received a total of 52 intra-articular injections of corticosteroid over a period of 14 months (Bentley and Goodfellow, 1969). Alarcon-Segovia and Ward (1966) cited the awesome example of a patient who received 3000 injections into the interphalangeal joints over a period of years and in whom joint disorganization ensued.

More convincing is the study by Chandler and Wright (1958) in which radiological deterioration occurred in more than half of 25 rheumatoid knee joints given four injections of hydrocortisone over a 48-week period despite symptomatic improvement. On the other hand, the same authors (Wright et al., 1960) reported no radiological deterioration in 38 osteoarthrotic knees given an identical course of hydrocortisone injections. Furthermore, in a review of 123 patients over a 4-year period Keagy and Keim (1967) could find no evidence of accelerated joint destruction even among patients given up to four injections at the same site, and Hollander (1970) observed a deleterious effect in less than $1 \%$ of a large number of subjects.

It has been well established that systemic corticosteroids may modify metabolism of cartilage and other tissues in animals. Denko and Bergenstal (1961) showed an inhibition by hydrocortisone of ${ }^{35} \mathrm{~S}$ incorporated in costal and articular cartilage of rats, and similar findings were later made by Anastassiades and Dziewiatkowski (1970). Decrease in the size of chondrocytes and cell death were observed by Silberberg et al. (1966) in the articular cartilage of mice given systemic cortisone. Layton (1951) 
reported that cortisone inhibited the synthesis of chondroitin sulphate by chick embryo and wound tissues in vitro, and Mankin et al. (1972) observed marked reduction of in vitro glycosaminoglycan synthesis by cartilage removed from cortisonetreated rabbits.

Reconstitution of cartilage matrix in rabbit pretreated with papain was delayed by intra-articular injection of prednisolone and other corticosteroids (McCluskey and Thomas, 1959) and intra-articular hydrocortisone was shown to decrease glycine ${ }^{3} \mathrm{H}$ incorporation in rabbit cartilage (Mankin and Conger, 1966). These studies suggest a local inhibition by steroids of both glycosaminoglycan and protein synthesis. Additional experiments of intraarticular injection of corticosteroids in rabbits have shown exaggerated degenerative joint changes comprising loss of cartilage, subchondral cysts, and fissuring, the extent of which was dependent on the number of injections (Salter et al., 1967; Moskowitz, et al., 1970).

Using single doses of methyl prednisolone equivalent to $200 \mathrm{mg}$ in a $60 \mathrm{~kg}$ man and far in excess of the usual amounts injected in human disease, we failed to reproduce the severe joint disorganization seen in rabbit joints. Minor degenerative changes were undoubtedly present in a large number of the knees but were also seen in an animal which had not undergone joint injection. Similar changes may also occur in rabbits not given intra-articular injections (Moskowitz et al., 1970).

The India ink preparations of the femoral condyles showed on some surfaces a pattern that was identical to the 'minimal fibrillation' seen in human joints when examined at random by the same technique (Meachim and Fergie, 1975).

The pattern of staining obtained by the critical electrolyte concentration technique was remarkably similar to that of mature human joints (Stockwell, 1970). In man, at least, the results of this histochemical procedure correlate with the distribution of keratan sulphate and chondroitin sulphate as measured biochemically (Stockwell and Scott, 1967). Evidence suggests that degeneration of cartilage is associated with an increase of chondroitin sulphate, a decrease of keratan sulphate, and little change in total glycosaminoglycan content (Mankin and Lippiello, 1971). However, this conflicts with earlier observations in which reduction of chondroitin sulphate was reported (Matthews, 1953). For this reason we thought that the properties of the Alcian blue method would allow detection of any change in either the total or relative proportions of glycosaminoglycans even in the absence of structural abnormalities. There was a tendency for staining with Alcian blue at one or both concentrations of magnesium chloride to be less intense in associatiog. with structural defects but there was no consistent pattern in the staining densities of the two concen $\overline{\vec{F}}$ trations relative to each other. It was not possibte to make any firm conclusion about proportiona changes of glycosaminoglycans. There was n⿳亠口冋丁 overall difference between the steroid-injected an control joints with regard to staining density.

The observations of Poswillo (1970) suggested tha्र steroid induced changes in primate joints might be transitory. We therefore attempted to examine this possibility by performing biopsies at an early stage of the experiment but could detect no abnormalites

After intra-articular injections of methyl prednisolone in man, absorption from the joint cavitg may allow the preparation to exert a systemic effect (Holden and Kendall, 1962). Assuming this occurret in the monkeys used in our experiment it could bo argued that the control joints were also exposed to corticosteroid. It is unlikely that such an effect influenced our findings because the histological and histochemical changes did not show any relationship to the frequency of injections, although a slight/y higher macroscopical score did obtain for the joints injected six times compared with those injected twice.

Our observations ao not imply that intra-articula corticosteroids in man are entirely devoid of the

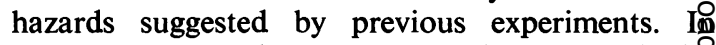
particular, the study does not examine the possibiition that a harmful effect may occur in cartilage alread compromised by inflammatory disease, as suggeste by Chandler and Wright (1958). Nevertheless our results do show a marked difference of response steroid injections in monkeys compared with the effects observed in rabbits in earlier experiment These results emphasize that an effect in one species cannot be readily extrapolated to another. To this. extent the experiment does not support the vie that intra-articular corticosteroid injections are invariably harmful. The evidence in man suggests that very frequent injections may have a deleterious effect on articular cartilage. Whether infrequent injectiors may also accelerate cartilage destruction is far from certain and it may be that the benefits of occasion injections in reducing synovial inflammation fage outweigh any effect of steroid on the articular surface्ట We are grateful for the expert assistance of Mr. Cat Hobbs and Mr. Bruce Bidewell, and to Actio Research for the Crippled Child for generows financial support.

\section{References}

Alarcon-Segovia, D., and Ward, L. E. (1966). Markẹ destructive changes occurring in osteoarthritic fingef 
joints after intra-articular injection of corticosteroids. Arthritis and Rheumatism, 9, 443-463.

Anastassiades, T., and Dziewiatkowski, D. (1970). The effect of cortisone on the metabolism of connective tissue in the rat. Journal of Laboratory and Clinical Medicine, 75, 826-839.

Bentley, G., and Goodfellow, J. W. (1969). Disorganisation of the knees following intra-articular hydrocortisone injections. Journal of Bone and Joint Surgery, 51B, 498-502.

Bullough, P., and Goodfellow, J. (1968). The significance of the fine structure of articular cartilage. Journal of Bone and Joint Surgery, 50B, 852-857.

Chandler, G. N., and Wright, V. (1958). Deleterious effect of intra-articular hydrocortisone. Lancet, 2, 661-633.

Chandler, G. N., Jones, D. T., Wright, V., and Hartfall, S. J. (1959). Charcot's arthropathy following intra-articular hydrocortisone. British Medical Journal, 1, 952-953.

Denko, C. W., and Bergenstal, D. M. (1961). Effects of growth hormone and corticosteroids on $\mathbf{S}^{\mathbf{3 5}}$ fixation in cartilage. Endocrinology, 69, 769-777.

Holden, G., and Kendall, P. H. (1962). The newer corticosteroids for local injection. Annals of Physical Medicine, 6, 178-182.

Hollander, J. L. (1970). Intrasynovial corticosteroid therapy in arthritis. Maryland State Medical Journal, 19, 62-66.

Keagy, R. D., and Keim, H. A. (1967). Intra-articular steroid therapy: repeated use in patients with chronic arthritis. American Journal of the Medical Sciences, 253, 45-51.

Layton, L. L. (1951). Effect of cortisone upon chondroitin sulfate synthesis by animal tissues. Proceedings of the Society for Experimental Biology and Medicine, 76, 596-598.

McCluskey, R. T., and Thomas, L. (1959). The removal of cartilage matrix in vivo by papain. Prevention of recovery with cortisone, hydrocortisone and prednisolone by a direct action on cartilage. American Journal of Pathology, 35, 819-828.

Mankin, H. J., and Conger, K. A. (1966). The acute effects of intra-articular hydrocortisone on articular cartilage in rabbits. Journal of Bone and Joint Surgery, 48A, 1383-1388.

Mankin, H. J., and Lippiello, L. (1971). The glycosaminoglycans of normal and arthritic cartilage. Journal of Clinical Investigation, 50, 1712-1719.

Mankin, H. J., Dorfman, H., Lippiello, L., and Zarins, A. (1971). Biochemical and metabolic abnormalities in articular cartilage from osteo-arthritic human hips. II. Correlation of morphology with biochemical and metabolic data. Journal of Bone and Joint Surgery, 53A, 523-537.
Mankin, H. J., Zarins, A., and Jaffe, W. L. (1972). The effect of systemic corticosteroids on rabbit articular cartilage. Arthritis and Rheumatism, 15, 593-599.

Matthews, B. F. (1953), Composition of articular cartilage in osteoarthritis. Changes in collasen: chondroitin sulphate ratio. British Medical Journal, 2, 660-661.

Meachim, G., and Fergie, I. A. (1975). Morphological patterns of articular cartilage fibrillation. Journal of Pathology, 115, 231-240.

Moskowitz, R. W., Davis, W., Sammarco, J., Mast, W., and Chase, S. W. (1970). Experimentally induced corticosteroid arthropathy. Arthritis and Rheumatism, 13, 236-243.

Poswillo, D. (1970). Experimental investigation of the effects of intra-articular hydrocortisone and high condylectomy on the mandibular condyle. Oral Surgery, Oral Medicine and Oral Pathology, 30, 161-173.

Rehder, E., and Enquist, I. F. (1967). Species differences in the response to cortisone in wounded animals. Archives of Surgery, 94, 74-78.

Salter, R. B., Gross, A., and Hall, J. H. (1967). Hydrocortisone arthropathy. An experimental investigation. Canadian Medical Association Journal, 97, 374-377.

Scott, J. E., and Dorling, J. (1965). Differential staining of acid glycosaminoglycans (mucopolysaccharides) by Alcian Blue in salt solutions. Histochemie, 5, 221-233.

Silberberg, M., Silberberg, R., and Hasler, M. (1966). Fine structure of articular cartilage in mice receiving cortisone acetate. Archives of Pathology, 82, 569-582.

Steinberg, C. L. R., Duthie, R. B., and Piva, A. E. (1962). Charcot-like arthropathy following intra-articular hydrocortisone. Journal of the American Medical Association, 181, 851-854.

Stockwell, R. A. (1970). Changes in the acid glycosaminoglycan content of the matrix of ageing human articular cartilage. Annals of the Rheumatic Diseases, 29, 509-515.

Stockwell, R. A., and Scott, J. E. (1967). Distribution of acid glycosaminoglycans in human articular cartilage. Nature, 215, 1376-1378.

Sweetnam, D. R., Mason, R. M., and Murray, R. O. (1960). Steroid arthropathy of the hip. British Medical Journal, 1, 1392-1394.

Wright, V., Chandler, G. N., Morison, R. A. H., and Hartfall, S. J. (1960). Intra-articular therapy in osteoarthritis. Comparison of hydrocortisone acetate and hydrocortisone tertiary butylacetate. Annals of the Rheumatic Diseases, 19, 257-261.

Zachariae, L. (1965). Deleterious effects of corticosteroids administered topically, in particular intra-articularly. Acta Orthopaedica Scandinavica, 36, 127-136. 